\title{
Ventricular bigeminy during balloon occlusion of carotico-cavernous fistula
}

\section{Surya Kumar Dube, Arati Rai', Jaikishan Anandani², Hemanshu Prabhakar}

Sir,

A 12-year-old, $39 \mathrm{~kg}$ American Society of Anaesthesiologists (ASA) grade I, male patient presented with proptosis of right eye ball since 6 months and tinnitus in right ear since 2 months. He had a history of head injury 8 months ago. He did not have any signs or symptoms of cardio-respiratory abnormality and his systemic and haematological examination were normal. He was diagnosed to have right carotico-cavernous fistula (CCF) and was scheduled for balloon occlusion of right CCF under general anaesthesia. In the neuroradiological suite pulse oximeter, Electrocardiography (ECG) and non-invasive blood pressure were attached. A standard anaesthetic technique using propofol, fentanyl and rocuronium for induction followed by sevoflurane and nitrous oxide for maintenance via laryngeal mask airway (LMA) was used. Following infiltration with $2 \%$ lignocaine, femoral access for the procedure was secured. The patient had stable haemodynamics for initial 45 minutes. However, during the inflation of balloon in the cavernous sinus, sudden bradycardia (heart rate decreased to 35 beats per minute from the initial value of 92 beats per minute) with hypotension (Blood Pressure $86 / 47 \mathrm{mmHg}$ from the initial value of $126 / 78 \mathrm{mmHg}$ ) and the ECG showed ventricular bigeminy (VB). The neuroradiologist was informed but brief interruption of the procedure could not correct the arrhythmia and hypotension. The bradycardia and hypotension responded to $0.6 \mathrm{mg}$ of intravenous (IV) atropine but the VB persisted. The arterial blood gas analysis was normal and there were no signs of inadequate depth of anaesthesia or hypoxemia. To treat the VB, we administered $2 \%$ lignocaine $1.5 \mathrm{mg} / \mathrm{kg}$ followed by infusion @ $2 \mathrm{mg} / \mathrm{min}$. The VB resolved within next 10 minutes. Rest of the procedure was uneventful and the patient was shifted to Intensive Care Unit (ICU) further management.

Balloon occlusion is one of the therapeutic options for CCF. ${ }^{[1]}$ The trigemino-cardiac reflex (TCR) is defined as the sudden onset of parasympathetic dysrhythmia, sympathetic hypotension, apnoea or gastric hypermotility resulting from stimulation of receptors on trigeminal afferent fibres including those of the peripherical branches. ${ }^{[2]}$ The different risk factors for TCR are hypercapnia, hypoxia, lighter plane of anaesthesia or drugs (beta blockers, calcium channel blockers or narcotics like sufentanil and alfentanil). ${ }^{[2]}$ In our case, the patient did not have any risk factors for TCR or VB. Stimulation of receptors in the ophthalmic and maxillary division of trigeminal nerve situated in the lateral wall of cavernous sinus can initiate TCR during neurointerventions for CCF and dural arteriovenous fistula ${ }^{[3]}$ and VB can occur during oculo-cardiac reflex, ${ }^{[4]}$ which is a variant of TCR. Ventricular bigeminy is a cardiac arrhythmia characterized by the occurrence of a normal heartbeat followed by a premature ventricular contraction. Sudden onset VB has an increased potential for ventricular fibrillation, ${ }^{[5]}$ and hence should be treated promptly. Lignocaine $(1.5 \mathrm{mg} / \mathrm{kg}$ followed by $1-4 \mathrm{mg} / \mathrm{min}$, if needed) is the treatment of choice for $\mathrm{VB}$ which is unresponsive to correcting the underlying abnormality. ${ }^{[5]}$ To the best of our knowledge, this is the first report of ventricular bigeminy resulting due to TCR during balloon occlusion for CCF. With this case report, we want to emphasise upon the fact that VB can occur as a part of TCR during balloon occlusion of CCF and may require lignocaine for resolution.

\section{REFERENCES}

1. Gemmete JJ, Chaudhary N, Pandey A, Ansari S. Treatment of carotid cavernous fistulas. Curr Treat Options Neurol 2010;12:43-53.

2. Arasho B, Sandu N, Spiriev T, Prabhakar H, Schaller B. Management of the trigeminocardiac reflex: Facts and own experience. Neurol India 2009;57:375-80.

3. Amiridze N, Darwish R. Hemodynamic instability during

Departments of Neuroanaesthesiology, Neurosciences Centre, All India Institute of Medical Sciences, New Delhi,

${ }^{1}$ Anaesthesia, Sikkim Manipal Institute of Medical Sciences, Tadong, Sikkim, ${ }^{2}$ Anaesthesiology, Max Super Speciality Hospital, I.P. Extension, New Delhi, India

Address for correspondence:

Dr. Surya Kumar Dube, Department of Neuroanaesthesiology, $7^{\text {th }}$ Floor C N Centre, All India Institute of Medical Sciences, New Delhi - 110029 ,

India. E-mail: surya.dube@yahoo.co.in 
treatment of intracranial dural arteriovenous fistula and carotid cavernous fistula with Onyx: Preliminary results and anesthesia considerations. J Neurointerv Surg 2009;1:146-50.

4. Alexander JP. Reflex disturbances of cardiac rhythm during ophthalmic surgery. Br J Ophthalmol 1975;59:518-24.

5. Hillel Z, Thys DM. Electrocardiography. In: Miller RD, editor, Miller's Anesthesia, $6^{\text {th }}$ ed. Philadelphia: Elsevier Churchill Livingstone; 2005. p. 1389-414.

\begin{tabular}{|l|l|}
\hline \multicolumn{2}{|c|}{ Access this article online } \\
\hline Quick Response Code: & Website: \\
\hline & www.jnaccjournal.org \\
\cline { 2 - 2 } & \\
\hline & \\
\hline
\end{tabular}

\section{“QUICK RESPONSE CODE” LINK FOR FULL TEXT ARTICLES}

The journal issue has a unique new feature for reaching to the journal's website without typing a single letter. Each article on its first page has a "Quick Response Code". Using any mobile or other hand-held device with camera and GPRS/other internet source, one can reach to the full text of that particular article on the journal's website. Start a QR-code reading software (see list of free applications from http://tinyurl.com/yzlh2tc) and point the camera to the QR-code printed in the journal. It will automatically take you to the HTML full text of that article. One can also use a desktop or laptop with web camera for similar functionality. See http://tinyurl.com/2bw7fn3 or http://tinyurl.com/3ysr3me for the free applications. 